\title{
Disseminated fungal sepsis in an extremely premature neonate
}

\author{
A Shenvi, ${ }^{1}$ A Mishra ${ }^{2}$ \\ ${ }^{1}$ Neonatal Unit, Birmingham Women's Hospital, Edgbaston, Birmingham, UK; \\ 2Department of Neonatology, Royal Bolton NHS Foundation Trust, Farnworth, Bolton, UK
}

Correspondence to Dr Asha Shenvi, ashashenvi@yahoo.com

\section{DESCRIPTION}

Disseminated fungal sepsis in an extremely premature neonate. An infant born at 25 weeks gestation was extubated to biphasic continuous positive airway pressure after 7 days. On day 8, she developed a periumbilical rash from which Candida was isolated. Topical miconazole and intravenous antibiotics were started in view of increased desaturations and thrombocytopenia. On day 11, Candida albicans was isolated from blood cultures and intravenous fluconazole was commenced. Cranial and renal ultrasound scans were normal. She became progressively more unwell, needing ventilation. On day 14 , she developed pulmonary haemorrhage. A cranial ultrasound scan showed several widespread circular echogenic lesions consistent with invasive fungal mycomas (figure 1). ${ }^{1}$

Although fluconazole provides good cerebrospinal fluid penetration, intravenous micafungin was added as broad spectrum antifungal therapy to provide cover for other strains of Candida in view of the clinical deterioration. Despite this, she became more unwell and intensive care was withdrawn.

Postmortem confirmed mycotic encephalitis (figure 2) with disseminated fungal sepsis within the liver, lungs and kidneys.

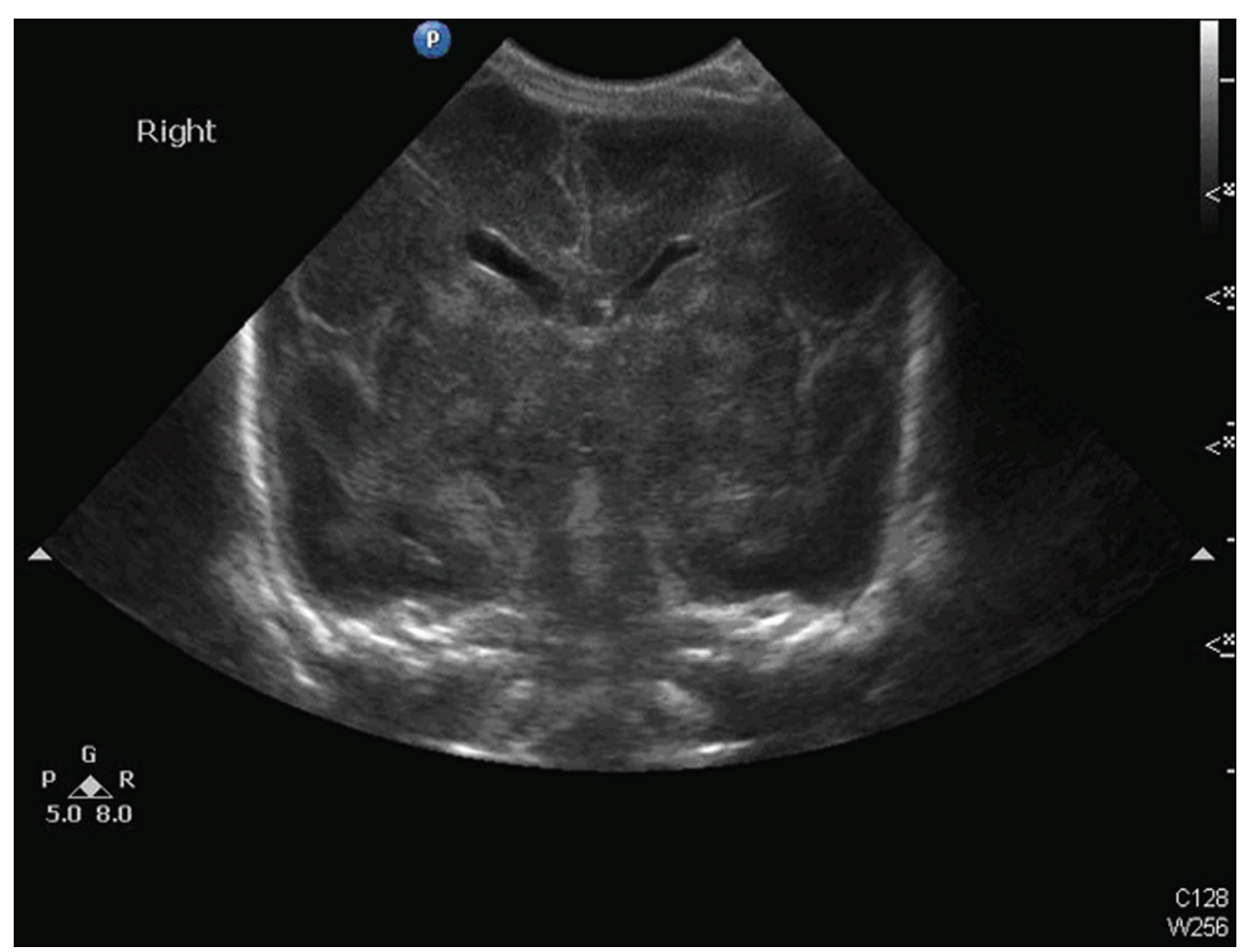

Figure 1 Bilateral widespread multiple spherical areas of increased echogenicity within the periventricular white matter and basal ganglia. 


\section{BMJ Case Reports}

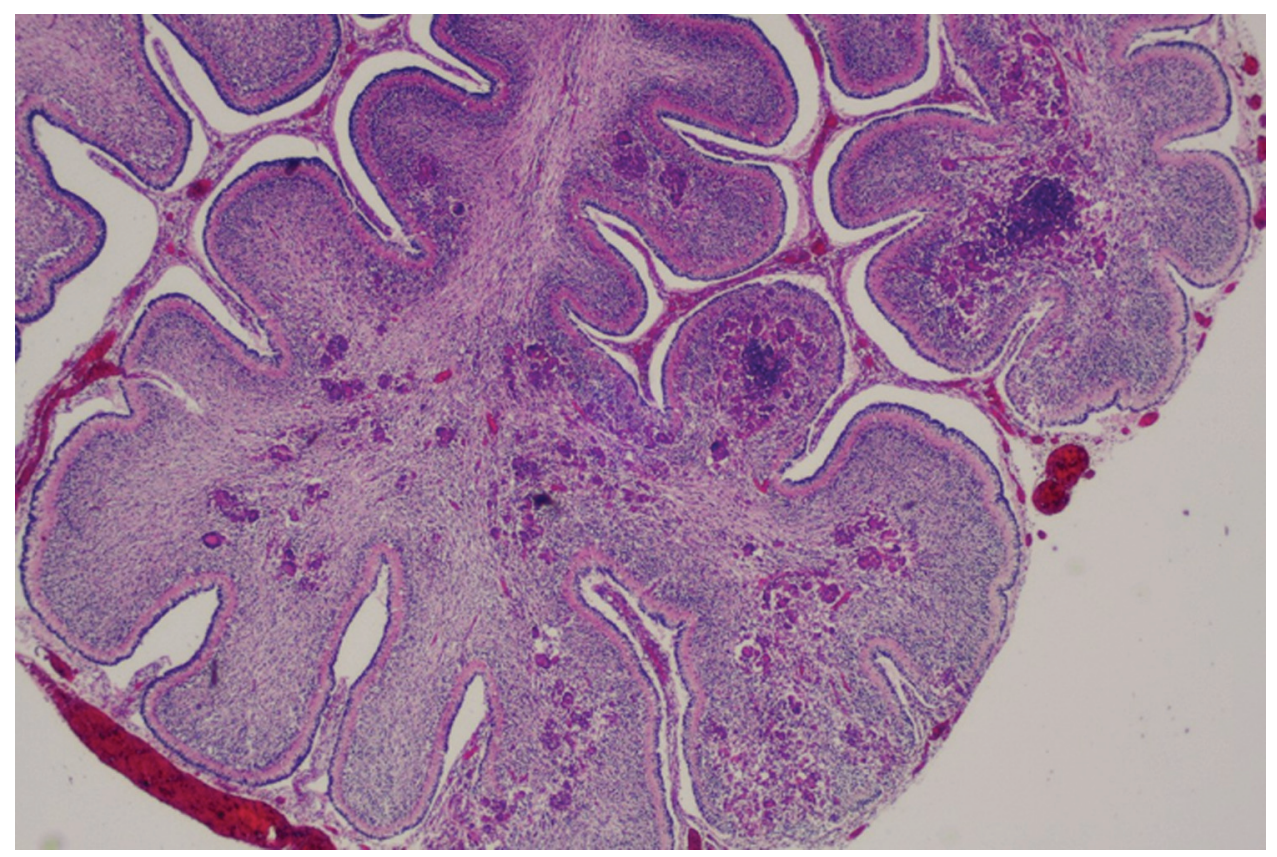

Figure 2 Multiple Candida granulomas within brain substance identified by grocott stain.

Acknowledgements The authors would like to thank Perinatal Pathology Department, Birmingham Women's Hospital.

Competing interests None.

Patient consent Obtained.

\section{REFERENCES}

1. Hunag CC, Chen CY, Yang HB, et al. Central nervous system candidiasis in

very low-birth-weight premature neonates and infants: US characteristics and histopathologic and MR imaging correlates in five patients. Radiology 1998;209:49-56.

2. Benjamin DK, Poole C, Steinbach WJ, et al. Pediatrics 2001: neonatal candidemia and end-organ damage: a critical appraisal of the literature using meta-analytic techniques. Pediatrics 2003;112:634-40.

3. Marcinkowski M, Bauer K, Stoltenburg-Didinger G, et al. Fungal brain abscesses in neonates: Sonographic appearances and corresponding histopathologic findings. J Clin Ultrasound 2001;29:417-21.

This pdf has been created automatically from the final edited text and images.

Copyright 2011 BMJ Publishing Group. All rights reserved. For permission to reuse any of this content visit http://group.bmi.com/group/rights-licensing/permissions.

BMJ Case Report Fellows may re-use this article for personal use and teaching without any further permission.

Please cite this article as follows (you will need to access the article online to obtain the date of publication).

Shenvi A, Mishra A. Disseminated fungal sepsis in an extremely premature neonate. BMJ Case Reports 2011;10.1136/bcr.10.2010.3378, date of publication

Become a Fellow of BMJ Case Reports today and you can:

- Submit as many cases as you like

- Enjoy fast sympathetic peer review and rapid publication of accepted articles

- Access all the published articles

- Re-use any of the published material for personal use and teaching without further permission

For information on Institutional Fellowships contact consortiasales@bmjgroup.com

Visit casereports.bmj.com for more articles like this and to become a Fellow 